\title{
Rectal perforation from cholesterol embolization syndrome
}

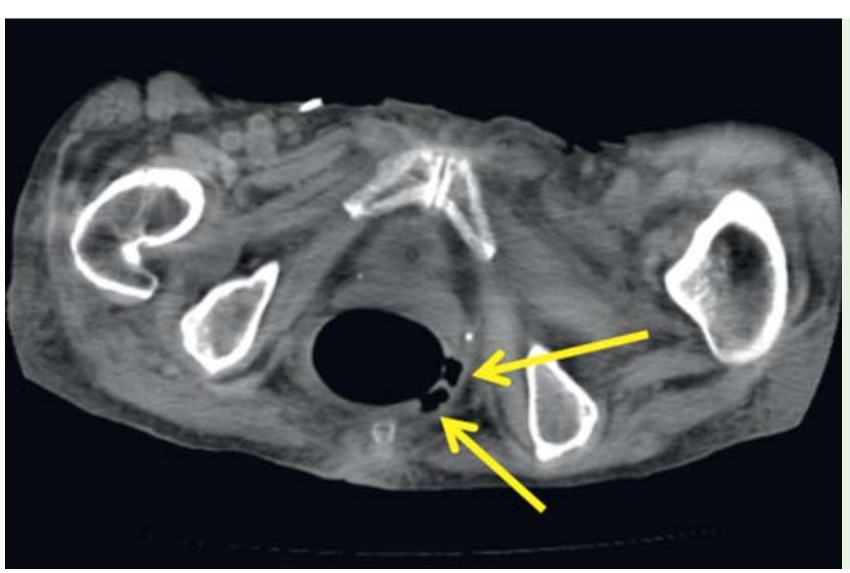

Fig. 1 Abdominal and pelvic computed tomography (CT) scan showing rectal perforation with irregular air density in the adipose tissue on the left side of the rectum (arrows).

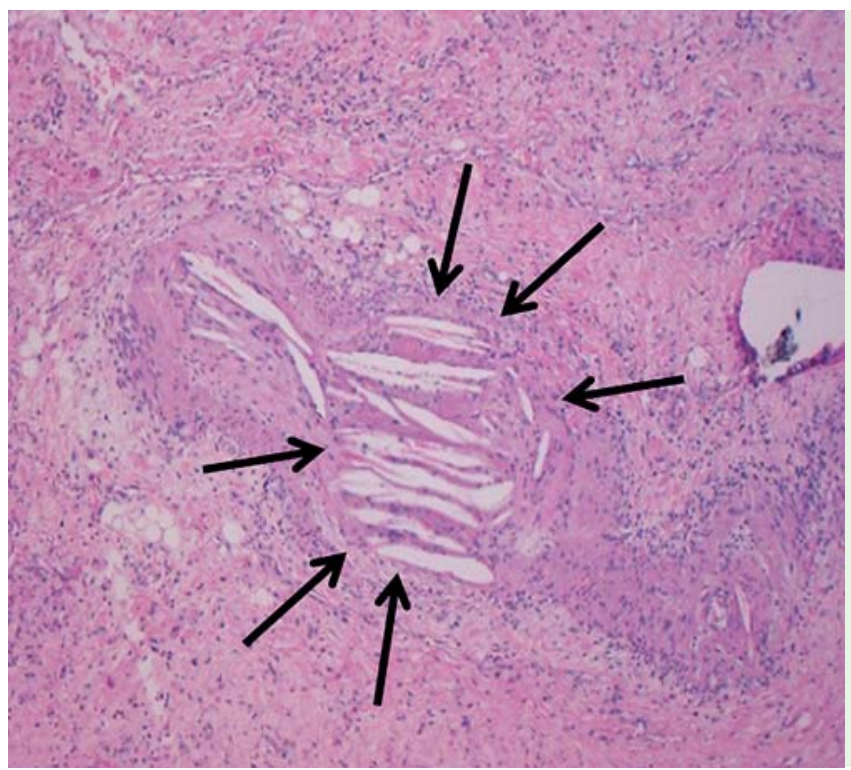

Fig. 3 Fibrous granulation tissue, small calcified deposits and emboli with cholesterol clefts were observed at the base of a rectal ulcer (arrows) (hematoxylin and eosin; $\times 200$ ).

Cholesterol embolization syndrome (CES) is a rare syndrome with a high incidence of morbidity and mortality [1]. Because of the variability in clinical presentations, the diagnosis is often difficult. CES presents as multiorgan dysfunction and should be considered in the differential diagnosis of the symptom complex after vascular thrombolytic therapy [2]. Skin and renal involvement are the most common presentations, such as livedo reticularis and rash [3]. CES of the digestive systems is not uncommon, with rates varying from $18 \%$ to $48 \%[4,5]$. We encountered a rare case of rectal perforation due to CES, which was diagnosed only after the patient had died.
A 91-year-old woman with rectal bleeding was admitted for shunt formation and hemodialysis for progressive renal failure. She suddenly had massive melena, and computed tomography showed rectal perforation, which was also suspected based on the communicating irregular air density in adipose tissue on the left side of the rectum ( $\bullet$ Fig. 1).

Colonoscopy revealed bleeding, perforation, and fistula formation in the rectum (๑ Fig. 2).

The rectal perforation was limited to the surrounding intrapelvic adipose tissue, and surgical treatment was planned, but the patient died of renal complications and disseminated intravascular coagula-

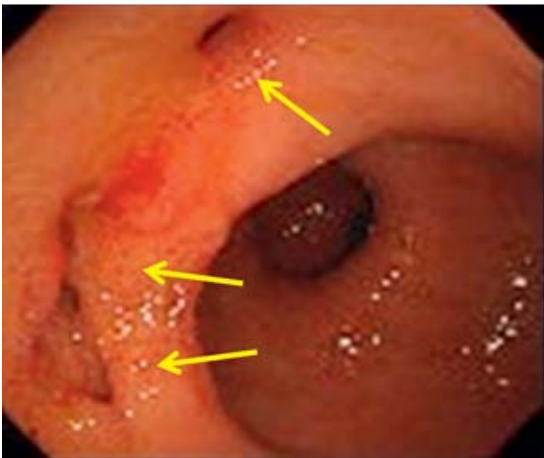

Fig. 2 A $9 \mathrm{~mm} \times 5 \mathrm{~mm}$ ulcer was found in the lower rectum, which was thought to be the perforation site (arrows).

tion. On pathologic examination, a $9 \mathrm{~mm} \times$ $5 \mathrm{~mm}$ ulcer was found in the lower rectum, and at the base of the ulcer, arteriolar cholesterol emboli with cholesterol clefts were observed along with granulation tissue ( Fig. 3).

Cholesterol emboli and clefts were also found in the spleen and renal arterioles. From these pathologic findings, a rectal perforation resulting from CES was diagnosed.

The diagnosis of CES can be confirmed by means of biopsy of the target organs [3]; the biopsy sections of the lesion areas demonstrate cholesterol emboli and clefts. A thorough clinical history and physical findings are important steps in establishing a diagnosis. A correct diagnosis is important because it may prevent inappropriate treatment of the patient [3-5].

\section{Competing interests: None}

\section{Endoscopy_UCTN_Code_CCL_1AD_2AJ}

\section{H. Mori ${ }^{1}$, H. Kobara ${ }^{1}$, M. Kobayashi ${ }^{1}$,}

A. Muramatsu' ${ }^{1}$, T. Nomura ${ }^{1}$, T. Yachida ${ }^{1}$, K. Izuishi², Y. Suzuki², J. Gong',

\section{T. Masaki}

1 Department of Gastroenterology and Neurology, Kagawa Medical University School of Medicine, Kagawa, Japan 2 Department of Gastroenterological Surgery, Kagawa Medical University School of Medicine, Kagawa, Japan 


\section{References}

1 Scolari F, Tardanico R, Zani R et al. Cholesterol crystal embolism: A recognizable cause of renal disease. Am J Kidney Dis 2000; 36: 1089-1109

2 Fukumoto $Y$, Tsutsui $H$, Tsuchihashi $M$ et al. The incidence and risk factors of cholesterol embolization syndrome, a complication of cardiac catheterization: a prospective study. J Am Coll Cardiol 2003; 42: 211 -216
3 Chaudhary K, Wall BM, Rasberry RD. Livedo reticularis: an underutilized diagnostic clue in cholesterol embolization syndrome. Am J Med Sci 2001; 321: $348-351$

4 Fijiyama A, Mori Y, Yamamoto $S$ et al. Multiple spontaneous small bowel perforations due to systemic cholesterol atheromatous embolism. Inter Med 1999; 38: 580-584

5 Anderson WR. Colon perforation due to cholesterol embolism. Hum Pathol 1991; 22: $839-841$

\section{Bibliography}

DOI $10.1055 / \mathrm{s}-0030-1255978$

Endoscopy 2010; 42: E352 -E353

(c) Georg Thieme Verlag KG Stuttgart · New York . ISSN 0013-726X

\section{Corresponding author}

\section{H. Mori}

Department of Gastroenterology and Neurology Kagawa University School of Medicine

1750-1 Ikenobe

Miki Kita Kagawa 761-0793

Japan

Fax: +81-87-891-2158

hiro4884@med.kagawa-u.ac.jp 